\title{
Women's and health professionals' preferences for prenatal tests for Down syndrome: a discrete choice experiment to contrast noninvasive prenatal diagnosis with current invasive tests
}

\author{
Melissa Hill, PhD ${ }^{1,2}$, Jane Fisher ${ }^{3}$, Lyn S. Chitty, MRCOG, PhD ${ }^{1,2}$ and Stephen Morris, PhD ${ }^{4,5}$
}

Purpose: To compare the preferences of women and health professionals for key attributes of noninvasive prenatal diagnosis for Down syndrome relative to current invasive tests.

Methods: A questionnaire incorporating a discrete choice experiment was used to obtain participants' stated preference for diagnostic tests that varied according to four attributes: accuracy, time of test, risk of miscarriage, and provision of information about Down syndrome only or Down syndrome and other conditions. Women and health professionals were recruited from five maternity services in England and a patient support group.

Results: Questionnaires from 335 women and 181 health professionals were analyzed. Safe tests, conducted early in pregnancy, with high accuracy and information about Down syndrome and other conditions were preferred. The key attribute affecting women's preferences for testing was no risk of miscarriage, whereas for health professionals it was accuracy.

Conclusions: Policies for implementing noninvasive prenatal diagnosis must consider the differences between women's and health professionals' preferences to ensure the needs of all stakeholders are met. Women's strong preference for tests with no risk of miscarriage demonstrates that consideration for safety of the fetus is paramount in decision making. Effective pretest counseling is therefore essential to ensure women understand the possible implications of results.

Genet Med 2012:14(11):905-913

Key Words: discrete choice experiment; Down syndrome; non-invasive prenatal diagnosis

\section{INTRODUCTION}

Currently in the United Kingdom, the National Screening Committee recommends that all pregnant women be offered a screening test for Down syndrome. Women who have a "highrisk" result are then offered an invasive diagnostic test, chorionic villus sampling or amniocentesis, which will tell them definitively whether or not the baby has Down syndrome. These invasive tests carry a risk of miscarriage of around $1 \%^{1}$ and cannot be performed until 11 weeks of pregnancy. The possibility of an alternative, noninvasive approach based on a maternal blood sample was raised with the discovery of cellfree fetal DNA in the maternal circulation more than a decade ago. ${ }^{2}$ Cell-free fetal DNA can be detected from 4 to 5 weeks gestation $^{3}$ and is rapidly cleared from the maternal circulation after delivery, making it pregnancy specific. ${ }^{4}$ The main barrier to developing prenatal tests based on cell-free fetal DNA has been in distinguishing the information specific to the fetus, as the majority of cell-free DNA in the circulation is maternal in origin. ${ }^{5}$ The technology underpinning noninvasive prenatal diagnosis (NIPD) for Down syndrome has advanced rapidly and several large scale validity studies have now been conducted to evaluate testing based on massively parallel sequencing. ${ }^{6-8}$ Moreover, the first NIPD tests for Down syndrome are now available commercially in some countries ${ }^{9}$ and considerations for more widespread implementation are being debated..$^{10}$ Validation of NIPD for Down syndrome using sequencing approaches is, however, ongoing and the test is not yet considered fully diagnostic as the small, but significant rate of false positives means an invasive test is still required to confirm a positive result. ${ }^{11}$

The clinical benefit of a NIPD test using cell-free fetal DNA is clear, as the risk of miscarriage associated with invasive testing is avoided. However, decisions on when and how NIPD for Down syndrome is introduced need to include considerations regarding other attributes of the test such as its accuracy and timing in pregnancy as it may be possible to perform NIPD several weeks earlier than current invasive tests. Another key difference between NIPD and invasive tests lies in the amount of information available from test results, with NIPD likely to provide targeted information (trisomy 21 only or trisomies 21,18 , and 13 only) as compared with an invasive test where information on all chromosomes can be provided through karyotyping. 
Understanding which test attributes are most highly valued by consumers and health professionals will help guide the implementation of NIPD into National Health Service (NHS) practice in a way that best meets the needs of all stakeholders.

Discrete choice experiments (DCEs) have been widely used in health-care research to examine stakeholder preferences. ${ }^{12}$ In a standard DCE, a series of hypothetical health-care options are presented and participants are asked to choose between them. As a result, DCEs reflect the complex nature of real-life decisions, allowing an exploration of people's preferences and their willingness to trade off one attribute against another. ${ }^{13}$ DCEs have been used previously to examine preferences for screening and diagnostic tests for Down syndrome, looking at attributes such as miscarriage risk, the timing of the test, and the type of information available from test results. ${ }^{14-18}$ Of note, in these studies a range of miscarriage risks were presented, but the option of a test with no risk of miscarriage was not included, which makes them inappropriate to assess preferences for NIPD. The results of the DCEs have had important implications for service delivery. For example, Bishop et al. ${ }^{14}$ found that health professionals placed greater value on earlier tests in pregnancy than women who would in fact prefer to wait for a result until later in pregnancy if the test were safer and more accurate. The aim of this study was to compare the preferences of women and health professionals for key attributes of diagnostic tests for Down syndrome, taking into account a range of possible clinical features of NIPD relative to invasive tests.

\section{MATERIALS AND METHODS}

Ethics approval was obtained from the National Research Ethics Service Committee (London-Hampstead REC Reference: 11/ H07201/12). Study design and analysis followed current guidelines for conducting DCEs. . $^{13,19,20}$

\section{Study sample}

Pregnant women were recruited from the obstetric ultrasound department London Hospital and three at regional NHS hospitals. This group was a convenience sample of Englishspeaking women who were attending for a second- or thirdtrimester ultrasound scan. All of the pregnant women invited to participate had either declined Down syndrome screening or had already undergone screening and had been given a lowrisk result. Pregnant women with a high-risk result were not included in this study to avoid any interference with their personal decision making regarding prenatal diagnosis. Women were given the questionnaire and had the option of reading two brief information sheets (see Supplementary Materials and Methods online). The first sheet described Down syndrome, current tests for Down syndrome screening and diagnosis, and future noninvasive tests; the second sheet described test accuracy. A researcher was available to discuss any questions. Women were asked to complete the questionnaire while waiting for their scan appointment. If there was insufficient time for this, they were invited to complete the questionnaire at home and return it by reply-paid post.
To broaden the range of opinions, pregnant and nonpregnant women who were members of the patient support group Antenatal Results and Choices (ARC) were invited to participate. The ARC membership includes women who have had to make decisions about invasive testing following a high-risk result as well as having to decide on management options following a diagnosis of Down syndrome. Women were recruited via an advertisement on the ARC website, which asked them to contact the researchers if they were interested in the study. The questionnaire was then sent by post with a prepaid envelope for returning it. Questionnaires were also available at the ARC Annual General Meeting in September 2011 where interested members were invited to take a questionnaire to complete and return by prepaid post.

Health professionals, primarily midwives and obstetricians, delivering antenatal care to women and who were likely to discuss options for Down syndrome screening and diagnostic testing were recruited from one London and four regional NHS hospitals. At all the hospitals, potential participants were approached in person and invited to complete a hard copy of the questionnaire. At one hospital, relevant staff groups were also e-mailed a study invitation and had the option of completing an online questionnaire.

\section{Questionnaire design}

Attributes for the DCE component of the questionnaire were selected after a literature review of prenatal testing for Down syndrome, which included several previously published DCEs. ${ }^{14-18}$ The chosen attributes into account key differences between NIPD and invasive tests and the associated levels clinically feasible ranges (Figure 1a). The DCE design follows the approach of Street and Burgess. ${ }^{21}$ Two attributes had three levels and two attributes had two levels. The number of possible combinations of attributes and levels was statistically reduced from $32\left(2^{3} \times 2^{2}\right)$ to 9 scenarios using an orthogonal fractional main effects design ${ }^{22}$ to give a practical number of choices for participants to complete in the questionnaire. A shift of one level was applied to the initial nine scenarios to create nine additional scenarios that were randomly paired to form the choice sets (see Supplementary Materials and Methods online). Across the choice sets, all levels of each attribute with equal frequency (level balance) and within each individual choice set there no overlap in attribute levels (minimal overlap). The statistical design was efficient in terms of maximizing the amount of information from respondents, given the number of attributes and levels $(\mathrm{D}$-efficiency $=99.79 \%){ }^{23}$ An additional question was included as an internal consistency check, with a clearly superior test as an option, giving a total of 10 pairwise choice sets (see Supplementary Materials and Methods online). The questionnaires for women asked about which test they would prefer to have and the questionnaires for health professionals asked about which test they would prefer to offer. Participants were asked to choose test A, test B, or neither (Figure 1b). The neither option was included to make the 


\begin{tabular}{|l|l|}
\hline Attribute & Levels \\
\hline Accuracy & $90 \%, 95 \%, 100 \%$ \\
Time of results (gestation in weeks) & $9,11,13$ \\
Risk of miscarriage & Small risk (1\%), No risk \\
Information gained from the test & Down syndrome, Down syndrome plus additional information \\
\hline
\end{tabular}

b

\begin{tabular}{|c|c|c|}
\hline Choice 1 & Test A & Test B \\
\hline Accuracy & $95 \%$ & $100 \%$ \\
\hline Time of results & 9 weeks & 11 weeks \\
\hline Risk of miscarriage & Small risk (1\%) & No risk \\
\hline Information from test & $\begin{array}{l}\text { Down's syndrome plus } \\
\text { additional information }\end{array}$ & Down's syndrome only \\
\hline
\end{tabular}

Figure 1 Discrete choice experiment design. (a) Attributes and levels used in the discrete choice experiment. (b) Example of a discrete choice experiment choice set.

choice more realistic, as in practice women may choose not to have a test.

The questionnaires included a description of the attributes and levels included in the DCE and a section asking participants to rank the four attributes in order of importance. Additional questions for women included age, ethnicity, education, parity, gestational age, and uptake of Down syndrome screening. Additional questions for health professionals included job title, years in role, age, and gender. The questionnaires took $\sim 20 \mathrm{~min}$ to complete. Questionnaires were piloted with 17 midwives and 20 women to determine whether they could be readily understood; participants were asked if there were any other important attributes of prenatal tests that were not covered in the questionnaire. Following this pilot, changes were made to the wording in the questionnaire describing the attributes, but not to the overall design of the experiment.

\section{Analysis}

The DCE preference data were analyzed for both women and health professionals using a conditional logit regression model. ${ }^{24}$ For data entry, to avoid misinterpretation ${ }^{19}$ the levels for accuracy and time of results coding were mean centered, and risk of miscarriage and information were effects coded. A constant term was included to reflect the "neither" option. ${ }^{25}$ The sign $(+$ or -$)$ of the coefficients generated in the regression analysis indicates the direction of the preference for each attribute. We anticipated positive coefficients for three attributes as we expected participants to prefer tests with greater accuracy, no risk of miscarriage, and comprehensive information. We anticipated a negative coefficient for the timing attribute, which would suggest preference for an earlier test.

The preferences of women were compared with those of health professionals. Additional subgroup analyses were performed to examine differences related to women's age $(<35$ or
235), screening uptake, how they were recruited (via ARC or in maternity units); and for health professionals, differences between midwives and obstetricians. In addition, we determined those women and health professionals who considered multiple attributes when choosing between tests ("traders") and those who made choices on the basis of one attribute only ("nontraders"). We then compared the women and health professionals who were "traders."

To explore the trade-offs the participants were willing to make between test attributes, we calculated the marginal rates of substitution. The marginal rates of substitution between two attributes is the ratio of their coefficients. This allows a direct assessment of how much of one attribute the participants are willing to trade for one unit of another attribute, and permits an easy comparison between different attributes on a common scale. ${ }^{19}$ We also used the regression results to calculate the predicted probability that tests with different combinations of the attributes and levels used in the choice sets would be selected. This allowed us to rank the tests in terms of their order of preference by the participants. ${ }^{19}$

The software package Stata 10.0 (StataCorp College Station, TX) was used to perform all analyses.

\section{Participants}

\section{RESULTS}

The response rate was $94.9 \%$ (318/335) for women recruited through maternity units and $61.5 \%(32 / 52)$ for those recruited through ARC. The response rate for health professionals was $54.5 \%$ (193/354). Questionnaires were excluded if the consistency question was not answered as expected (women $n=5$, and health professionals $n=8$ ) or if the respondents did not complete the choice set (women $n=10$, and health professionals $n=4$ ). Consequently, questionnaires from a total of 335 women and 181 health professionals were included in the analysis. Demographic information is summarized in Table 1. 
Table 1 Demographic data

Women

Total $(n=335)^{\mathrm{a}}$

Recruiting center

Hospital 1

$78(23.28 \%)$

Hospital 2

$37(11.04 \%)$

Hospital 3

$98(29.25 \%)$

Hospital 4

$90(26.87 \%)$

ARC

$32(9.49 \%)$

Age

Mean (SD)

$30.94(6.29)$

Ethnicity

White or white British

$297(88.6 \%)$

Black or black British

$8(2.39 \%)$

Asian, East Asian, or Asian British

$15(4.48 \%)$

Other

$10(2.99 \%)$

Highest qualification

No qualification

$8(2.39 \%)$

GCSE or equivalent

$71(21.19 \%)$

A-level or equivalent

$63(18.81 \%)$

Degree or equivalent

$184(54.93 \%)$

Number of children

None

$163(48.66 \%)$

1

$112(33.43 \%)$

2 or more

$58(17.31 \%)$

Do you have a child with Down syndrome?

Yes

0

No

$327(97.6 \%)$

Does anyone you know have a child with Down syndrome?

Yes

$75(22.39 \%)$

No

$252(75.22 \%)$

Current pregnancy

Currently pregnant

$302(90.15 \%)$

Gestation (weeks) — mean (SD)

$24.86(7.07)$

Down syndrome screening in this pregnancy

Have had or will have screening

$245(81.13 \%)$

Do not intend to have screening

$55(18.21 \%)$

Health professionals

Total $(n=181)^{\text {a }}$

Recruiting center

Hospital 1

$26(14.36 \%)$

Hospital 2

$19(10.50 \%)$

Hospital 3

$42(23.20 \%)$

Hospital 4

$33(18.23 \%)$

Hospital 5

$61(33.70 \%)$

Age

Mean (SD)

$40.12(9.16)$

Gender

Female

$153(84.53 \%)$

Male

$25(13.81 \%)$
Table 1 Continued

$\begin{array}{lr}\begin{array}{l}\text { Profession } \\ \text { Obstetrician }\end{array} & 53(29.28 \%) \\ \text { Midwife } & 117(64.64 \%) \\ \text { Other (sonographer, nurse consultant, etc.) } & 9(4.97 \%) \\ \text { Years in profession } & \\ <5 & 48(26.51 \%) \\ 6-15 & 58(32.04 \%) \\ 16-25 & 50(27.62 \%) \\ 26-35 & 17(9.39 \%)\end{array}$

ARC, Antenatal Results and Choices; GCSE, General Certificate of Secondary Education.

aValues reported as $n$ (\%) unless otherwise stated. Totals may not add to $100 \%$ due to missing responses.

\section{Ranking of attributes}

Ranking of attributes varied between participants with $66 \%$ of women ranking safety highest, whereas $58 \%$ of health professionals ranked accuracy as the most important (see Supplementary Results online).

\section{Regression results}

The positive coefficients suggest that both women and health professionals prefer a test with greater accuracy, no risk of miscarriage, and full information (Table 2A). The negative coefficient for time of results indicates the preference for an earlier test. These results support the a priori expectations providing support for the theoretical validity of the models. All coefficients were statistically significant for both groups. Comparison of regression results for professionals and women confirmed the differences observed from rankings with statistically significant differences in the coefficients for accuracy, timing, and no risk of miscarriage (Table 2A).

Further subgroup comparisons indicated that women aged $\geq 35$ years placed a greater emphasis on accuracy than younger women, and women who had undergone Down syndrome screening in their current pregnancy differed from those who had declined Down syndrome screening in the emphasis they placed on test timing and information (Table 2B). Women recruited through ARC were more likely to choose tests with greater accuracy and full information (Table 2B). There were no significant differences in preferences between obstetricians and midwives (see Supplementary Results online).

Of the respondents defined as nontraders, 16 (4.78\%) women, but no health professionals chose neither for all options; 110 (32.84\%) women and $13(7.18 \%)$ health professionals chose tests based on no miscarriage risk; 15 (4.48\%) women and $33(18.2 \%)$ health professionals chose tests based on highest accuracy; $1(0.30 \%)$ woman and no health professionals chose tests based on earliest timing; and 19 (5.67\%) women and $7(3.87 \%)$ health professionals chose tests based on full information being available. When comparing traders, the only significant difference between the groups was for accuracy (Table 2B). 


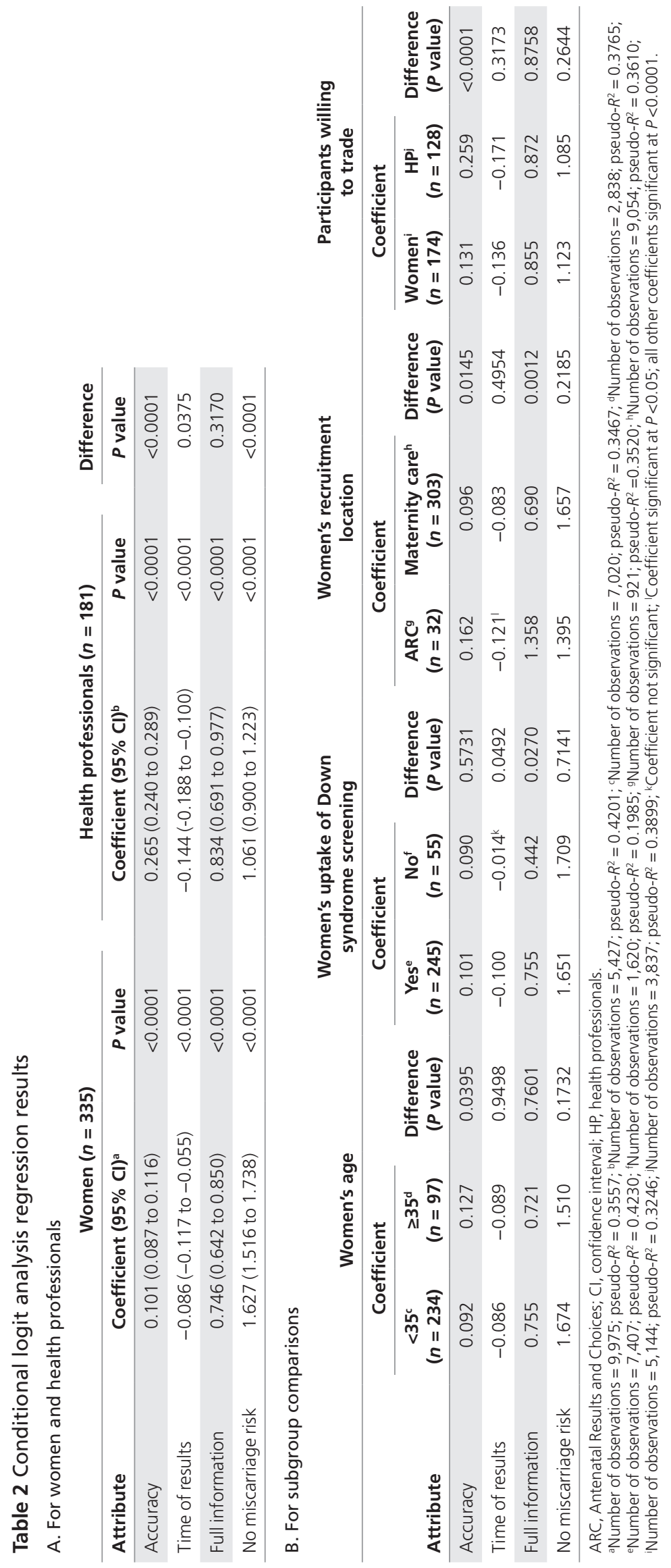




\section{Marginal rates of substitution}

Calculation of the marginal rates of substitution confirmed women's strong preference for a test with no risk of miscarriage, as they were prepared to wait more than twice as long and accept $12 \%$ lower accuracy for a test that had no risk of miscarriage as compared with health professionals (Table 3 ).

\section{Predicted probabilities}

Tests were ranked in order of preference by calculating the mean probability of choosing a given test (Table 4A). Two tests with attributes similar to current invasive tests were included in the analysis for comparison with a series of tests with the possible attributes of NIPD. The rankings show that women are prepared to accept tests with lower accuracy if there is no risk of miscarriage (Table 4A), whereas health professionals prefer to offer a test that is accurate, even if it has a small risk of miscarriage (Table $4 \mathrm{~B}$ ).

\section{DISCUSSION}

The introduction of NIPD for Down syndrome into routine clinical practice is imminent. Implementation of any test needs to consider more than laboratory robustness and should take account of the needs and preferences of service users and providers in order to ensure the development of appropriate care pathways. In this study, we have examined the preferences of women and health professionals for diagnostic tests for Down syndrome. Not surprisingly, both women and health professionals were found to prefer safe tests that were conducted early in pregnancy with high accuracy and gave information about other conditions in addition to Down syndrome. However, there were significant differences between the women and health professionals in the relative values they placed on safety, accuracy, and time of results, with women prepared to wait longer and accept lower accuracy if the test had no risk of miscarriage.

Table 3 Marginal rates of substitution

\begin{tabular}{lccccc} 
& \multicolumn{2}{c}{$\begin{array}{c}\text { Number of weeks respondents are } \\
\text { prepared to wait }\end{array}$} & & \multicolumn{2}{c}{$\begin{array}{c}\text { Reduction in accuracy (\%) respondents are } \\
\text { prepared to accept }\end{array}$} \\
\cline { 2 - 3 } & Women & Health professionals & & Women & Health professionals \\
\hline Test with no risk of miscarriage & $18.92(1.627 /-0.086)$ & $7.37(1.061 /-0.144)$ & & $16.11(1.627 / 0.101)$ & $4.00(1.061 / 0.265)$ \\
Test with full information & $8.67(0.746 /-0.086)$ & $5.79(0.834 /-0.144)$ & & $7.39(0.746 / 0.101)$ & $3.15(0.834 / 0.265)$ \\
\hline Test with 5\% greater accuracy & $5.87(0.101 /-0.086 \times 5)$ & $9.20(0.265 /-0.144 \times 5)$ & & - \\
\hline
\end{tabular}

Table 4 Probability analysis

\section{Ranking Mean probability}

A. For women

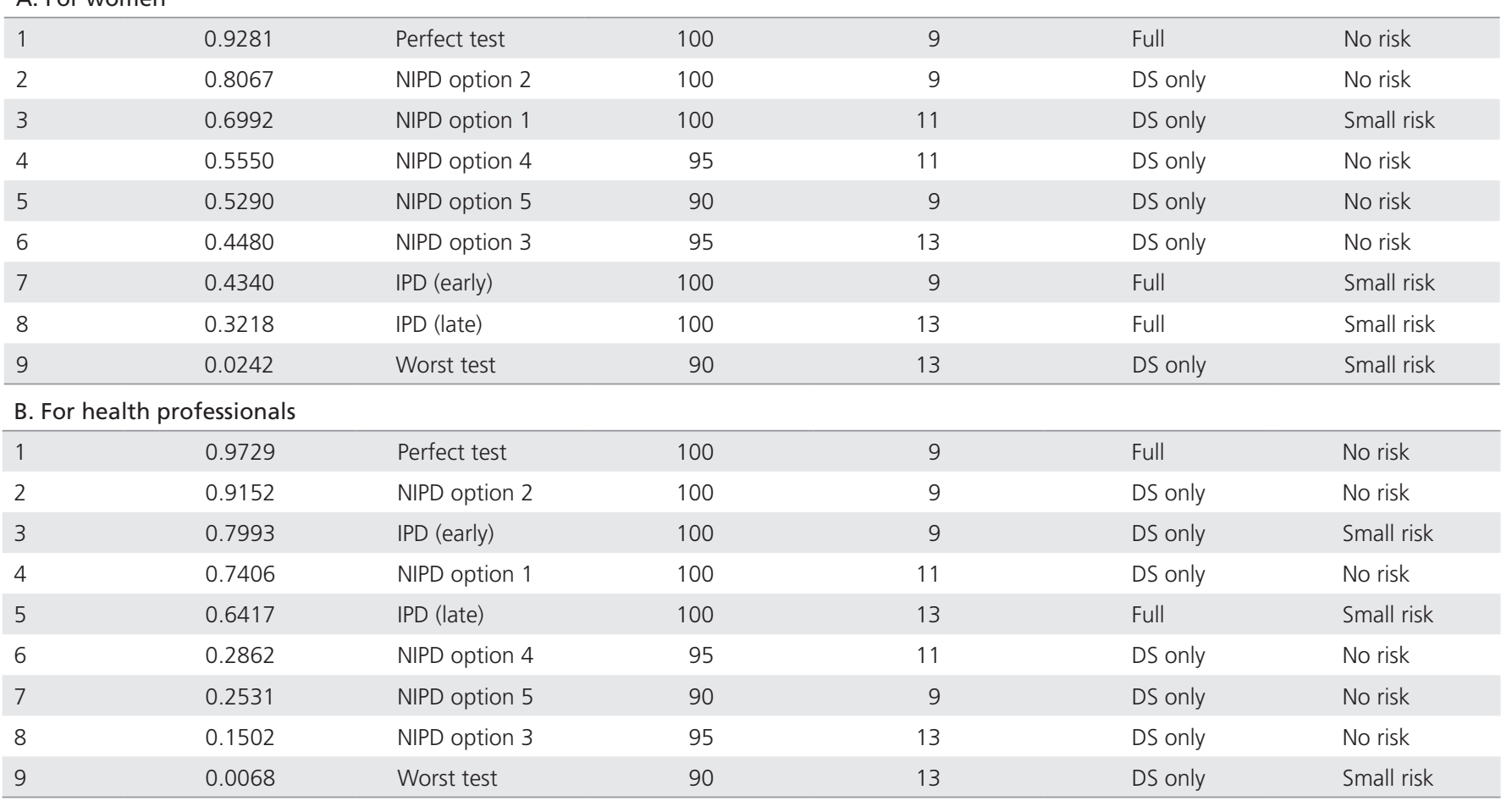

DS, Down syndrome; IPD, invasive prenatal diagnosis; NIPD, noninvasive prenatal diagnosis.

$\begin{array}{llll}\text { Option } & \text { Accuracy (\%) } & \text { Time (weeks) } & \text { Information }\end{array}$ 
Previous DCE studies looking at prenatal testing for Down syndrome have also found differences between women's and health professionals' preferences. Studies conducted in the United Kingdom ${ }^{14}$ and Australia ${ }^{15}$ have shown health professionals valued earlier timing of tests whereas women emphasized safety. One possibility to account for the differences is that women may be less likely to look objectively at multiple test attributes and may not have the same understanding of the implications of the differences in attribute levels, as they are unlikely to think about tests involving their unborn baby in this way. ${ }^{14,15}$ Health professionals are also more likely to be aware of the growing body of literature, exploring the ethical and psychosocial concerns associated with NIPD. ${ }^{26-30}$ Consequently, the value placed on accuracy by health professionals as compared with women in this study may, at least in part, be due to differences in their existing knowledge and concerns about the implementation of NIPD. To an extent, this view is supported by the observation that, in contrast to women recruited through antenatal clinics, those recruited through ARC, all of whom had experience of adverse results in a previous pregnancy and hence prior experience, had a greater preference for accuracy and a test that gave more information. Experiential knowledge has previously been shown to play an important role in women's decisions regarding prenatal testing ${ }^{31}$ and personal experience may account for the differences seen between these groups. We also found that women $\geq 35$ had a stronger preference for tests with higher accuracy than women $<35$. This is similar to the observation of Mulvey et al., ${ }^{32}$ who found that older women ( $>37$ ) valued Down syndrome screening tests with the highest detection rate, as compared to younger women, who preferred tests with the lowest possible false-positive rate.

Having a test with no risk of miscarriage was clearly a major consideration for women when making decisions about the prenatal tests with which they were presented. Of note, over one-third of the women in this study chose tests based only on the fact there was no risk of miscarriage and did not trade on the other test attributes. This finding corresponds with recent research from the United States that reported that pregnant women thought the most important feature of NIPD would be safety of the fetus (75\%), followed by accuracy (13\%) and early availability of results (7\%). ${ }^{33}$ Similarly, a UK study found that women who have had NIPD for fetal sex determination described safety as the most important feature of the test. ${ }^{34}$

For many women, the miscarriage risk associated with invasive testing is a psychological barrier to diagnostic testing for Down syndrome. ${ }^{27,35}$ If the miscarriage risk is removed, women may feel more inclined to have a test. ${ }^{35}$ In addition, health professionals have been found to view NIPD more like screening than an invasive diagnostic test, suggesting that they may not provide the same level of information and counseling as they would for an invasive diagnostic test. ${ }^{36}$ The results of our study demonstrate that the option of a test with no miscarriage risk is indeed highly influential for women making decisions regarding prenatal testing. The predicted probability analysis shows that women ranked the attributes of the current invasive tests lower than the theoretical NIPD tests, regardless of test accuracy. In this study there were 50 pregnant women who had chosen not to have Down syndrome screening in their current pregnancy; of these only 12 indicated that they would not have any of the tests presented to them on the questionnaire by selecting "neither" for all of the choice options. This suggests that it is possible that many of the women who currently decline Down syndrome screening may choose to undergo testing if there is no risk of miscarriage associated with the definitive diagnosis. However, more research is needed to determine whether, if faced with a real-life decision, the uptake of Down syndrome testing would increase if NIPD was available.

Differences in the relative values women and health professionals place on test attributes are important considerations for the implementation of NIPD as health professionals play key roles in evaluating health innovations and establishing policy. ${ }^{37,38}$ Ideally, the implementation of NIPD will take all stakeholder views into consideration. Furthermore, health professionals must recognize that their views about prenatal tests may differ from those of the women with whom they discuss testing. The attitudes of health professionals have been shown to impact the uptake of Down syndrome screening, ${ }^{39}$ and in the recent study of pregnant women's interest in NIPD conducted in the United States, one in five women said that they would do what their health professional recommended..$^{33}$

Implementation of NIPD for Down syndrome into routine antenatal care will depend on many factors, including test accuracy, costs, and care pathways. ${ }^{10} \mathrm{~A}$ key factor for the successful introduction of NIPD will be the development of approaches to counseling and strategies for information provision that will facilitate informed decision making. As safety is so clearly predominant in women's minds, care must be taken in counseling to spell out all the differences between available testing options or women may not think beyond the issue of safety and accept testing without realizing the possible implications of the results. For this reason, it will also be critical to have structures in place for when abnormal results are given to help parents to understand the clinical implications of the findings and to provide individualized support for decision making. ${ }^{40,41}$

\section{Limitations}

In this study we attempted to gather the preferences of a diverse cross-section of women by recruiting from four different hospitals in disparate regions of the United Kingdom. However, a number of issues may limit the generalizability of our findings. For example, the overwhelming majority of pregnant women who took part in this study were white, and more than half were highly educated and held a degree qualification or equivalent. We considered only four attributes of prenatal tests. Real-life choices about prenatal tests also consider other factors such as false positives, access to tests, costs, and counseling. Consideration could also be given to whether preferences for diagnostic tests were influenced by having to choose between different types of procedures, for example, 
a blood draw as compared with an invasive test, which is often associated with pain and anxiety. ${ }^{42}$ Furthermore, cost is frequently included as an attribute in DCEs to estimate willingness to pay. Although cost will be an important consideration for future research in this area, at present the actual cost of NIPD is uncertain. The technology underpinning NIPD for Down syndrome is rapidly becoming cheaper. In addition, a key determinant of the cost of NIPD will be how it is placed in the care pathway, as this will establish how many people are offered testing. ${ }^{10}$ Furthermore, in this study we were considering implementation into routine NHS care, a service that does not charge for testing.

It is also important to note that, as for any stated preference study, the choices made in the questionnaire do not necessarily reflect the choices that would be made if participants were faced with a real-life decision about testing. Most of the pregnant women completing the questionnaire were at 20 or more weeks gestation and were invited to participate as they had either chosen not to have Down syndrome screening or were found to be at low risk. As such, their stated preferences may be different from the choices they would make earlier in pregnancy or if they had received a high-risk screening result. Finally, the DCE design does not look into the reasoning behind the choices made or give insight into how the tests were perceived. An in-depth understanding of the thoughts of pregnant women and preferences regarding NIPD is needed and this could be obtained through qualitative studies.

\section{Conclusions}

Women and health professionals differ in the value they place on test accuracy and safety when making choices about diagnostic tests for Down syndrome. Policies for the implementation of NIPD for Down syndrome need to consider these differences to ensure the needs of all stakeholders are met. Women's strong preference for tests with no risk of miscarriage demonstrate that consideration for the safety of the fetus has the potential to outweigh other test attributes when making decisions regarding prenatal testing. This highlights the need for effective pretest counseling and informed consent processes to ensure women understand the parameters of the test and the possible implications of NIPD.

\section{ACKNOWLEDGMENTS}

The National Institute for Health Research (NIHR) under its Programme Grants for Applied Research scheme (RP-PG-0707-10107) and the NIHR Comprehensive Clinical Research Network funded the study. L.S.C. is partially funded by the Great Ormond Street Hospital Children's Charity. S.M. is partially funded by NIHR Biomedical Research Centre at University College London. We are grateful to the women and health professionals who participated in the study. This presentation presents independent research commissioned by the National Institute for Health Research (NIHR) under the Programme Grants for Applied Research programme RP-PG-0707-10107 (the "RAPID" project). The views expressed in this presentation are those of the authors and not necessarily those of the NHS, the NIHR, or the Department of Health. We also thank the local principal investigators and researchers at each hospital site: Sarah Bailey at Princess Anne Hospital, Southampton; Rita Arya and Rachel Crone at Warrington Hospital; Jane Radford at Queen's Hospital Burton; Helen Cameron and Patricia Wake at City Hospitals Sunderland; and Kerry McCall, Madhavi Karunaratna, Cecilia Compton, and Frida Forya at University College London Hospital. We thank Isobel Giblin for help with data entry. All authors contributed to study design, recruitment protocols, data collection, and interpretation. L.S.C. and S.M. conceived the study. M.H. and S.M. designed the discrete choice experiment and analyzed the data. M.H. coordinated and managed the research process and wrote the first draft of the manuscript. All authors contributed to and approved the final manuscript.

\section{DISCLOSURE}

The authors declare no conflict of interest.

\section{REFERENCES}

1. Mujezinovic F, Alfirevic Z. Procedure-related complications of amniocentesis and chorionic villous sampling: a systematic review. Obstet Gynecol 2007;110:687-694.

2. Lo YM, Corbetta N, Chamberlain PF, et al. Presence of fetal DNA in maternal plasma and serum. Lancet 1997;350:485-487.

3. Lo YM, Hjelm NM, Fidler C, et al. Prenatal diagnosis of fetal RhD status by molecular analysis of maternal plasma. N Engl J Med 1998:339:1734-1738.

4. Lo YM, Zhang J, Leung TN, Lau TK, Chang AM, Hjelm NM. Rapid clearance of fetal DNA from maternal plasma. Am J Hum Genet 1999;64:218-224

5. Lo YM, Tein MS, Lau TK, et al. Quantitative analysis of fetal DNA in maternal plasma and serum: implications for noninvasive prenatal diagnosis. Am J Hum Genet 1998:62:768-775.

6. Chiu RW, Akolekar R, Zheng YW, et al. Non-invasive prenatal assessment of trisomy 21 by multiplexed maternal plasma DNA sequencing: large scale validity study. BMJ 2011;342:c7401.

7. Palomaki GE, Kloza EM, Lambert-Messerlian GM, et al. DNA sequencing of maternal plasma to detect Down syndrome: an international clinical validation study. Genet Med 2011;13:913-920.

8. Bianchi DW, Platt LD, Goldberg JD, Abuhamad AZ, Sehnert AJ, Rava RP. Genome-wide fetal aneuploidy detection by maternal plasma DNA sequencing. Obstet Gyneco/ 2012;119:890-901.

9. Sequenom. http://www.sequenomcmm.com/home/, 2011.

10. Chitty LS, Hill M, White H, Wright D, Morris S. Noninvasive prenatal testing for aneuploidy-ready for prime time? Am J Obstet Gynecol 2012;206:269-275.

11. Benn P, Borrell A, Cuckle H, et al. Prenatal Detection of Down Syndrome using Massively Parallel Sequencing (MPS): a rapid response statement from a committee on behalf of the Board of the International Society for Prenatal Diagnosis, 24 October 2011. Prenat Diagn 2011; 32:1-2.

12. de Bekker-Grob EW, Ryan M, Gerard K. Discrete choice experiments in health economics: a review of the literature. Health Econ 2012;21:145-172.

13. Ryan M, Gerard K, Amaya-Amaya M (eds). Using Discrete Choice Experiments to Value Health and Health Care. Springer: Dordrecht, The Netherlands, 2008.

14. Bishop AJ, Marteau TM, Armstrong D, et al. Women and health care professionals' preferences for Down's Syndrome screening tests: a conjoint analysis study. BJOG 2004;111:775-779.

15. Lewis SM, Cullinane FM, Carlin JB, Halliday JL. Women's and health professionals' preferences for prenatal testing for Down syndrome in Australia. Aust N Z J Obstet Gynaeco/ 2006;46:205-211.

16. Lewis SM, Cullinane FN, Bishop AJ, Chitty LS, Marteau TM, Halliday JL. A comparison of Australian and UK obstetricians' and midwives' preferences for screening tests for Down syndrome. Prenat Diagn 2006; 26:60-66.

17. Ryan M, Diack J, Watson V, Smith N. Rapid prenatal diagnostic testing for Down syndrome only or longer wait for full karyotype: the views of pregnant women. Prenat Diagn 2005;25:1206-1211. 
18. Chan YM, Sahota DS, Leung TY, Choy KW, Chan OK, Lau TK. Chinese women's preferences for prenatal diagnostic procedure and their willingness to trade between procedures. Prenat Diagn 2009;29:12701276.

19. Lancsar E, Louviere J. Conducting discrete choice experiments to inform healthcare decision making: a user's guide. Pharmacoeconomics 2008;26:661-677.

20. Bridges JF, Hauber AB, Marshall D, et al. Conjoint analysis applications in health-a checklist: a report of the ISPOR Good Research Practices for Conjoint Analysis Task Force. Value Health 2011;14:403-413.

21. Street $D$, Burgess L, Viney R, Louviere J. Designing discete choice experiments for health care. In: Ryan M, Gerard K, Amaya-Amaya M (eds). Using Discrete Choice Experiments to Value Health and Health Care. Springer: Dordrecht, The Netherlands, 2008:47-72.

22. Hahn G, Shapiro S. A Catalogue and Computer Program for the Design and Analysis of Orthoganol Symmetric and Asymmetric Fractional Factorial Experiments. General Electric Research and Development Center: Schenectady, New York, 1966.

23. Street D, Burgess L. Discrete Choice Experiments (computer software). University of Technology: Sydney, 2007. http://crsu.science.uts.edu.au/ choice/. Accessed October 2011.

24. McFadden D. Conditional logit analysis of qualitative choice behavior. In: Zarembka P (ed). Frontiers in Econometrics. Academic Press: New York, 1974:105-142.

25. Haaijer R, Kamakura W, Wedel M. The "no-choice" alternative in conjoint choice experiments. Int J Res Mark 2001;43:93-106.

26. Wright CF. Cell-free Fetal Nucleic Acids for Non-invasive Prenatal Diagnosis. Report of the UK Expert Working Group. PHG Foundation [online], 2009. http://www. phgfoundation.org/reports/4985.

27. Benn PA, Chapman AR. Practical and ethical considerations of noninvasive prenatal diagnosis. JAMA 2009;301:2154-2156.

28. de Jong A, Dondorp WJ, de Die-Smulders CE, Frints SG, de Wert GM Non-invasive prenatal testing: ethical issues explored. Eur J Hum Genet 2010;18:272-277.

29. de Jong A, Dondorp WJ, Frints SG, de Die-Smulders CE, de Wert GM Advances in prenatal screening: the ethical dimension. Nat Rev Genet 2011:12:657-663.
30. Deans Z, Newson AJ. Should non-invasiveness change informed consent procedures for prenatal diagnosis? Health Care Anal 2011;19: 122-132.

31. Etchegary $H$, Potter $B$, Howley $H$, et al. The influence of experiential knowledge on prenatal screening and testing decisions. Genet Test 2008;12:115-124.

32. Mulvey S, Zachariah R, Mcllwaine K, Wallace EM. Do women prefer to have screening tests for Down syndrome that have the lowest screen-positive rate or the highest detection rate? Prenat Diagn 2003;23:828-832.

33. Tischler R, Hudgins L, Blumenfeld YJ, Greely HT, Ormond KE. Noninvasive prenatal diagnosis: pregnant women's interest and expected uptake. Prenat Diagn 2011:31:1292-1299.

34. Lewis $C$, Hill M, Skirton H, Chitty L. Fetal sex determination using free fetal DNA: Service users' experiences and preferences for how the service should be offered in clinical practice. Prenat Diagn 2012; e-pub ahead of print 10 May 2012.

35. Newson AJ. Ethical aspects arising from non-invasive fetal diagnosis Semin Fetal Neonatal Med 2008:13:103-108.

36. van den Heuvel A, Chitty L, Dormandy E, et al. Will the introduction of non-invasive prenatal diagnostic testing erode informed choices? An experimental study of health care professionals. Patient Educ Couns 2010:78:24-28.

37. Lehoux P, Denis JL, Rock M, Hivon M, Tailliez S. How medical specialists appraise three controversial health innovations: scientific, clinical and social arguments. Sociol Health IIIn 2010;32:123-139.

38. Grosse SD, Rogowski WH, Ross LF, Cornel MC, Dondorp WJ, Khoury MJ. Population screening for genetic disorders in the 21st century: evidence, economics, and ethics. Public Health Genomics 2010:13:106-115.

39. Dormandy E, Marteau TM. Uptake of a prenatal screening test: the role of healthcare professionals' attitudes towards the test. Prenat Diagn 2004;24:864-868

40. Fisher J. First-trimester screening: dealing with the fall-out. Prenat Diagn 2011;31:46-49.

41. Fisher J. Supporting patients after disclosure of abnormal first trimester screening results. Curr Opin Obstet Gynecol 2012;24:109-113.

42. Bot-Robin V, Sendon S, Bourzoufi K, et al. Maternal anxiety and pain during prenatal diagnostic techniques: a prospective study. Prenat Diagn $2012 \cdot 32 \cdot 562-568$ 